\title{
Statyba
}

\section{COMPARISON OF COMPUTER-AIDED INTEGRATION TECHNIQUES WHEN OBTAINING INITIAL DISPLACEMENTS MATRIX FOR GEOMETRICALLY NON-LINEAR LAMINATED FINITE ELEMENT}

\section{Kulinič MSc (Eng)}

To cite this article: V. Kulinič MSc (Eng) (2001) COMPARISON OF COMPUTER-AIDED INTEGRATION TECHNIQUES WHEN OBTAINING INITIAL DISPLACEMENTS MATRIX FOR GEOMETRICALLY NON-LINEAR LAMINATED FINITE ELEMENT, Statyba, 7:5, 352-358, DOI: 10.1080/13921525.2001.10531753

To link to this article: https://doi.org/10.1080/13921525.2001.10531753

Published online: 30 Jul 2012.

Submit your article to this journal $\llbracket$

Џ Article views: 35 


\section{KOMPIUTERINIŲ INTEGRAVIMO TECHNOLOGIJŲ PALYGINIMAS SUDARANT GEOMETRIŠKAI NETIESINIO SLUOKSNIUOTOJO BAIGTINIO ELEMENTO PRADINIŲ POSLINKIŲ MATRICA}

\section{Kulinič}

Vilniaus Gedimino technikos universitetas

\section{Ivadas}

Statyboje ir kitose technikos srityse pastaruoju metu naudojama vis daugiau kompozitiniu ortotropinių konstrukcinių elementų. Sprendžiant pakankamai plonụ sluoksniuotujų statybinès ir kitos paskirties plokščiu skaičiavimo uždavinius, rezultatai dažnai būna netikslūs, jeigu laikomasi prielaidos, kad konstrukcijos elementų poslinkiai ir deformacijos yra labai maži.

Daugelyje žinomų komercinių ir mokslinių skaičiuojamuju paketų, tokiu kaip ABAQUS, ALGOR, ANSYS, COSMOS/M, nerealizuotas geometrinis netiesiškumas sluoksniuotoms plokštèms [1-4]. Šia kryptimi vykdomi tyrimai ir yra sukurta daug programu, tačiau kompozitinèms (sluoksniuotosioms) konstrukcijoms modeliuoti dažniausiai kuriamos tokios metodikos, kurias galima sèkmingai taikyti tik tam tikriais konkrečiais atvejais [5].

Vienintelis bendrojo pobūdžio baigtinis elementas sluoksniuotosioms ortotropinèms lenkiamosioms plokštèms, kuriam nekeliami jokie formos, sluoksniu storiu, medžiagu fizikinių bei mechaninių charakteristikų, ortotropiškumo ašių krypties, apkrovimo būdo ir kraštinių sąlygu reikalavimai, yra TRIPLT [6]. Tačiau iki šiol šiam pakankamai sudètingam elementui, turinčiam 50 laisvès laipsnių, nebuvo realizuotas geometrinis netiesiškumas.

Atliekamų tyrimų tikslas - pagal elementą TRIPLT sukurti universalụ geometriškai netiesini sluoksniuotaji elementą, kuris gali būti naudojamas ivairiausioms (iskaitant ir gelžbetonines) plokštèms modeliuoti.

Realizuojant geometrini netiesiškumą daugiausia dèmesio skiriama liestinei standumo matricai, kuri yra svarbiausia vykstant iteraciniams procesams. Kadangi kiekviename iteracijos žingsnyje su ja atliekami ịvairūs veiksmai, todèl galima teigti, kad skaičiavimo modelio efektyvumas labiausiai priklausys nuo liestinès standumo matricos sudarymo ir apdorojimo algoritmų efektyvumo. Šioms matricoms sudaryti taikoma kompiuterinès algebros technologija.

Straipsnyje parodyta, kaip žinomam tiesiniam elementui TRIPLT pritaikomas geometrinis netiesiškumas, apibūdinta liestinè standumo matrica geometriškai netiesiniam elementui ir pateiktos pradinių poslinkių matricos išraiškos.

Paprogramiai pradinių poslinkių matricai skaičiuoti išvesti taikant kompiuterinę algebrą. Straipsnyje aprašytos kompiuterinio integravimo procedūros ir lyginami integravimo metodai.

\section{Baigtinis elementas TRIPLT}

Sluoksniuotojo baigtinio elemento TRIPLT geometrinès matricos gaunamos naudojant normuotasias $L$-koordinates $[7,8]$. Poslinkiai ir posūkiai elemento viduje išreiškiami, naudojant mazginius poslinkius (posūkius), ju gradientus ir poslinkius (posūkius) elemento viduje [7].

Atsižvelgiant ì tiesinę ir netiesinę dedamąsias, sluoksniuotojo baigtinio elemento TRIPLT deformacijas galima užrašyti taip:

$$
\boldsymbol{\varepsilon}=\left\{\begin{array}{c}
\boldsymbol{\varepsilon}_{0}^{p l} \\
\boldsymbol{\varepsilon}_{0}^{b} \\
\boldsymbol{\varepsilon}_{0}^{s}
\end{array}\right\}+\left\{\begin{array}{c}
\boldsymbol{\varepsilon}_{L}^{p l} \\
\mathbf{0} \\
\mathbf{0}
\end{array}\right\}=\left(\left[\left[\begin{array}{c}
B^{p l} \\
B^{b} \\
B^{s}
\end{array}\right]\right]+\left[\begin{array}{c}
{\left[B_{L}^{p l}\right.} \\
{[0]} \\
{[0]}
\end{array}\right]\right) \psi=[\cdot \mathcal{B}] \psi,(1)
$$

$\varepsilon_{0}^{p l}$ - tiesinè membraniniu deformaciju dalis; $\varepsilon_{0}^{b}-$ lenkimo deformacijos (kreiviai); $\varepsilon_{0}^{s}$ - šlyties deformacijos; $\varepsilon_{L}^{p l}$ - netiesinè membraninių deformacijų dalis; $\psi=\left\{\Psi_{u}, \Psi_{v}, \Psi_{v^{\prime}}, \Psi_{\theta 1}, \psi_{\theta 2}\right\}^{T}$ - visu mazginių poslinkiụ ir posūkiu vektorius; 


$$
\left.\left[\begin{array}{l}
B^{p l} \\
B^{b} \\
B^{s}
\end{array}\right]\right]=\left[B_{L}^{c}\right]-\text { geometrinès matricos tiesiné da- }
$$

lis, kuri susideda iš trijų submatricu, atitinkančiu membranines, lenkimo ir šlyties deformacijas:

$\left[\begin{array}{ccccc}\mathbf{H}_{.1}^{T}[F]^{-1} & \mathbf{0}^{T} & \mathbf{0}^{T} & \mathbf{0}^{T} & \mathbf{0}^{T} \\ \mathbf{0}^{T} & \mathbf{H}_{2}^{T}[F]^{-1} & \mathbf{0}^{T} & \mathbf{0}^{T} & \mathbf{0}^{T} \\ \mathbf{H}_{.2}^{T}[F]^{-1} & \mathbf{H}_{1}^{T}[F]^{-1} & \mathbf{0}^{T} & \mathbf{0}^{T} & \mathbf{0}^{T} \\ \mathbf{0}^{T} & \mathbf{0}^{T} & \mathbf{0}^{T} & -\mathbf{H}_{1}^{T}[F]^{-1} & \mathbf{0}^{T} \\ \mathbf{0}^{T} & \mathbf{0}^{T} & \mathbf{0}^{T} & \mathbf{0}^{T} & -\mathbf{H}_{2}^{T}[F]^{-1} \\ \mathbf{0}^{T} & \mathbf{0}^{T} & \mathbf{0}^{T} & -\mathbf{H}_{2}^{T}[F]^{-1} & -\mathbf{H}_{1}^{T}[F]^{-1} \\ \mathbf{0}^{T} & \mathbf{0}^{T} & \mathbf{H}_{2}^{T}[F]^{-1} & \mathbf{0}^{T} & -\mathbf{H}^{T}[F]^{-1} \\ \mathbf{0}^{T} & \mathbf{0}^{T} & \mathbf{H}_{1 .}^{T}[F]^{-1} & -\mathbf{H}^{T}[F]^{-1} & \mathbf{0}^{T}\end{array}\right]$

$\mathbf{H}^{T}=\left\{L_{1}^{3}, L_{2}^{3}, L_{3}^{3}, L_{1}^{2} L_{2}, L_{2}^{2} L_{3}, L_{3}^{2} L_{1}\right.$,

$\left.L_{1} L_{2}^{2}, L_{2} L_{3}^{\frac{2}{3}}, L_{3} L_{1}^{2}, L_{1}, L_{2}, L_{3}\right\}$ - normuotuju koordinačiu

vektorius; $\quad \mathbf{H}_{, 1}^{T} \equiv \frac{\partial \mathbf{H}^{T}}{\partial \mathbf{x}}, \mathbf{H}_{, 2}^{T} \equiv \frac{\partial \mathbf{H}^{T}}{\partial \mathbf{y}}-$ jo išvestinès;

$[F]$ - konfigūracijos matrica, kurios išraišką galima rasti literatūroje [7];

$\left[\begin{array}{c}{\left[B_{L}^{p l}\right.} \\ {[0]} \\ {[0]}\end{array}\right]=\left[B_{L}^{e}\right]-$ geometrinès matricos netiesinè dalis.

Remiantis geometriškai netiesinių baigtinių elementu teorija [7], netiesinè membraninių deformacijų dalis gali būti užrašyta taip:

$$
\begin{aligned}
& \boldsymbol{\varepsilon}_{L}^{p l}=\frac{1}{2}\left[\begin{array}{cc}
\mathbf{H}_{.1}^{T}[F]^{-1} \boldsymbol{\psi}_{w} & \mathbf{0} \\
\mathbf{0} & \mathbf{H}_{.2}^{T}[F]^{-1} \boldsymbol{\psi}_{w} \\
\mathbf{H}_{.2}^{T}[F]^{-1} \boldsymbol{\psi}_{w} & \mathbf{H}_{.1}^{T}[F]^{-1} \boldsymbol{\psi}_{w}
\end{array}\right] \times \\
& \left\{\begin{array}{l}
\mathbf{H}_{.1}^{T}[F]^{-1} \\
\mathbf{H}_{.2}^{T}[F]^{-1}
\end{array}\right\} \boldsymbol{\psi}_{w}=\left[B_{L}^{p l}\right]^{*} \boldsymbol{\psi}_{w} .
\end{aligned}
$$

Taip gaunama geometrinès matricos netiesinès dalies $\left[B_{L}^{e}\right]$ submatrica:

$$
\left[B_{L}^{p l}\right]^{k}=\left\{\begin{array}{c}
\mathbf{H}_{, 1}^{T}[F]^{-1} \boldsymbol{\psi}_{w} \mathbf{H}_{, 1}^{T}[F]^{-1} \\
\mathbf{H}_{, 2}^{T}[F]^{-1} \boldsymbol{\psi}_{w} \mathbf{H}_{, 2}^{T}[F]^{-1} \\
\mathbf{H}_{, 2}^{T}[F]^{-1} \boldsymbol{\psi}_{w} \mathbf{H}_{, 1}^{T}[F]^{-1}+\mathbf{H}_{, 1}^{T}[F]^{-1} \boldsymbol{\psi}_{w} \mathbf{H}_{, 2}^{T}[F]^{-1}
\end{array}\right\}
$$

Visi kiti matricos $\left[B_{L}^{e}\right]$ elementai yra nuliniai vektoriai:

$$
\left[B_{L}^{e}\right]=\left[\begin{array}{ccccc}
\left\{\begin{array}{c}
\mathbf{0}^{T} \\
\mathbf{0}^{T} \\
\mathbf{0}^{T}
\end{array}\right] & \left\{\begin{array}{c}
\mathbf{0}^{T} \\
\mathbf{0}^{T} \\
\mathbf{0}^{T}
\end{array}\right\} & {\left[B_{L}^{p l}\right]^{k}} & \left.\begin{array}{c}
\mathbf{0}^{T} \\
\mathbf{0}^{T} \\
\mathbf{0}^{T}
\end{array}\right\} & \left.\begin{array}{c}
\mathbf{0}^{T} \\
\mathbf{0}^{T} \\
\mathbf{0}^{T}
\end{array}\right] \\
\mathbf{0}^{T} & \mathbf{0}^{T} & \mathbf{0}^{T} & \mathbf{0}^{T} & \mathbf{0}^{T} \\
\mathbf{0}^{T} & \mathbf{0}^{T} & \mathbf{0}^{T} & \mathbf{0}^{T} & \mathbf{0}^{T} \\
\mathbf{0}^{T} & \mathbf{0}^{T} & \mathbf{0}^{T} & \mathbf{0}^{T} & \mathbf{0}^{T} \\
\mathbf{0}^{T} & \mathbf{0}^{T} & \mathbf{0}^{T} & \mathbf{0}^{T} & \mathbf{0}^{T}
\end{array}\right]
$$

Jégos ir momentai, veikiantys sluoksniuotojoje plokštejje, skaičiuojami pagal žinomas išraiškas $[9,10]$, o sluoksniuotosios plokštès membraniniú, lenkimo ir šlyties itempimų atstojamuju vektorius gali būti užrašytas taip:

$$
\boldsymbol{\sigma}=\left[\mathscr{T}\left\{\begin{array}{c}
\varepsilon_{x, 0}+\varepsilon_{x, L} \\
\varepsilon_{y, 0}+\varepsilon_{y, L} \\
\varepsilon_{x y, 0}+\varepsilon_{x y, L} \\
-\kappa_{x} \\
-\kappa_{y} \\
-2 \kappa_{x y} \\
\gamma_{y z} \\
\gamma_{x z}
\end{array}\right\}=[G]\left(\varepsilon_{0}+\varepsilon_{L}\right)=[\mathscr{G}] \boldsymbol{\varepsilon}\right.
$$

[〕] - bendroji medžiagos tamprumo matrica:

$$
[\mathscr{C}]=\left[\begin{array}{lll}
{[A]} & {[B]} & {[0]} \\
{[B]} & {[D]} & {[0]} \\
{[0]} & {[0]} & {[\bar{A}]}
\end{array}\right] .
$$

Submatricos $[A],[B],[D]$ ir $[\bar{A}]$ gaunamos iš jègų ir momentų išraišku, naudojant integravimo procedūras $[9,10]$.

\section{Liestinè standumo matrica}

Remiantis baigtinių elementụ teorija [7], geometriškai netiesinès baigtinių elementụ sistemos lygtis yra:

$$
\left[K_{T}(\psi)\right] \psi=\mathbf{P},
$$

$\left[K_{T}(\psi)\right]$ - liestinè (tangentinè) standumo matrica, priklausanti nuo mazginiu poslinkiu vektoriaus $\psi$ ir susidedanti iš iprastinès tiesines tampriosios standumo matricos $\left[K_{0}\right]$ ir dvieju pakopinių standumo matricu!: 
pradiniu itempimu matricos $\left[K_{\sigma}\right]$, kuri priklauso nuo einamosios ittempimu būsenos, ir pradiniu poslinkiu (arba dideliụ poslinkiụ) matricos $\left[K_{L}\right]$, kuri tiesiškai ir kvadratiškai priklauso nuo poslinkių.

Baigtinio elemento pradiniu poslinkiụ matrica:

$$
\begin{aligned}
& {\left[K_{L}^{e}\right]=\int_{\Delta}\left[B_{0}^{e}\right]^{T}[\mathscr{Y}]\left[B_{L}^{e}\right] d \Delta+} \\
& \int_{\Delta}\left[B_{L}^{e}\right]^{T}[\mathscr{T}]\left[B_{0}^{e}\right] d \Delta+\int_{\Delta}\left[B_{L}^{e}\right]^{T}[\mathscr{T}]\left[B_{L}^{e}\right] d \Delta
\end{aligned}
$$

arba išreiškiant bendrosios tamprumo matricos submatricomis (7):

$$
\begin{gathered}
{\left[K_{L}^{e}\right]=\int_{\Delta}\left[B^{p l}\right]^{T}[A]\left[B_{L}^{b}\right] d \Delta+} \\
\int_{\Delta}\left[B^{b}\right]^{T}[B]\left[B_{L}^{b}\right] d \Delta+\int_{\Delta}\left[B_{L}^{b}\right]^{T}[A]\left[B^{p l}\right] d \Delta+ \\
\int_{\Delta}\left[B_{L}^{b}\right]^{T}[B]\left[B^{b}\right] d \Delta+\int_{\Delta}\left[B_{L}^{b}\right]^{T}[A]\left[B_{L}^{b}\right] d \Delta .
\end{gathered}
$$

\section{Pradinių poslinkių matrica}

Pradiniụ poslinkių matricai gauti iš (10) naudojamos (10×10) dydžio bazinès matricos [7]:

$$
\begin{gathered}
{\left[T_{i, j k}\right]=[F]^{T} \int_{\Delta} \mathbf{H}_{, i} \mathbf{H}_{, j}^{T}[F]^{T} \boldsymbol{\psi}_{w} \mathbf{H}_{, k}^{T} d \Delta[F]^{T} \text { ir }} \\
{\left[T_{i j, k l}\right]=} \\
{[F]^{-T} \int_{\Delta} \mathbf{H}_{, i} \boldsymbol{\psi}_{w}^{T}[F]^{-T} \mathbf{H}_{, j} \mathbf{H}_{, k}^{T}\left[F \Gamma^{-T} \boldsymbol{\psi}_{k}, \mathbf{H}_{, l}^{T} d \Delta[F]^{-T}\right.}
\end{gathered}
$$

$$
(i, j, k, l=1,2)
$$

Visa pradiniu poslinkiu matrica $(50 \times 50)$ susideda iš devynių $(10 \times 10)$ dydžio submatricų:

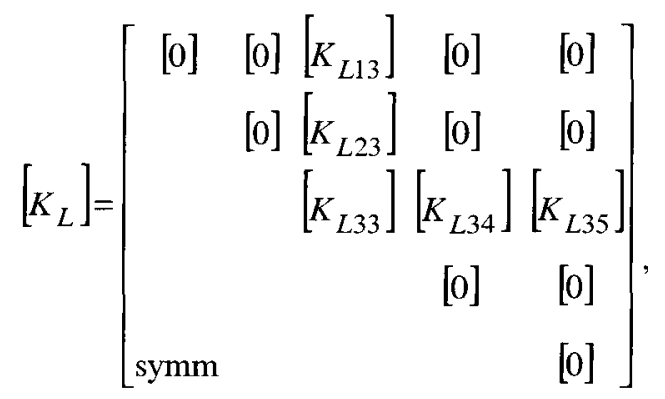

čia:

$\left[K_{L 13}\right]=A_{11}\left[T_{1,11}\right]+A_{12}\left[T_{1,22}\right\rfloor+A_{26}\left[T_{2,22}\right\rfloor+$ $A_{66}\left(T_{2,21}\right]+\left[T_{2,12}\right)+A_{16}\left(\left[T_{2,11}\right]+\left[T_{1,21}\right]+\left[T_{1,12}\right]\right)$
$\left[K_{L 23}\right]=A_{12}\left[T_{2,11}\right]+A_{16}\left[T_{1,11}\right]+A_{22}\left[T_{2,22}\right]+$ $A_{66}\left(\left[T_{1,21}\right]+\left[T_{1,12}\right]\right)+A_{26}\left(\left[T_{1,22}\right]+\left[T_{2,21}\right]+\left[T_{2,12}\right]\right)$

$$
\begin{aligned}
& {\left[K_{L 34}\right]=-B_{11}\left[T_{1,11}\right]^{T}-B_{12}\left[T_{1,22}\right]^{T}-B_{26}\left[T_{2,22}\right]^{T}-} \\
& B_{66}\left(\left[T_{2,21}\right]^{T}+\left[T_{2,12}\right]^{T}\right) \\
& B_{16}\left(\left[T_{2,11}\right]^{T}+\left[T_{1,21}\right]^{T}+\left[T_{1,12}\right]^{T}\right)
\end{aligned}
$$

$\left[K_{L 35}\right]=-B_{12}\left[T_{2,11}\right]-B_{16}\left[T_{1,11}\right]^{T}-B_{22}\left[T_{2,22}\right]^{T}-$ $B_{66}\left(\left[T_{1,21}\right]^{T}+\left[T_{1,12}\right]^{T}\right)-$

$B_{26}\left(\left[T_{1.22}\right]^{T}+\left[T_{2,21}\right]^{T}+\left[T_{2,12}\right]^{T}\right)$

$$
\begin{aligned}
& {\left[K_{L 33}\right]=A_{11}\left[T_{11,11}\right]+A_{22}\left[T_{22,22}\right]+} \\
& A_{12}\left(\left[T_{11,22}\right]^{T}+\left[T_{11,22}\right]\right)+ \\
& A_{16}\left(\left[T_{11,21}\right]^{T}+\left[T_{11,12}\right]^{T}+\left[T_{11,21}\right]+\left[T_{11,12}\right]\right)+ \\
& A_{26}\left(\left[T_{12,22}\right]+\left[T_{21,22}\right]+\left[T_{12,22}\right]^{p}+\left[T_{21,22}\right]^{T}\right)+ \\
& A_{66}\left(\left[T_{12,21}\right]+\left[T_{12,12}\right]^{T}+\left[T_{12,12}\right]+\left[T_{21,12}\right]\right)
\end{aligned}
$$

$A_{i j}$ ir $B_{i j}$ yra skaliariniai bendrosios tamprumo matricos (7) komponentai, o kokybiškas bazinių matricu išraiškas galima gauti tik taikant kompiuterinę algebrą [11], naudojant analizini arba skaitinị integravima.

\section{Pradinių poslinkių matricos sudarymas, taikant kompiuterinę algebrą}

$$
\text { Bazines matricos }\left[T_{i, j k}\right](i, j, k=1,2) \text { ir }\left[T_{i j, k l}\right]
$$
$(i, j, k, l=1,2)$ gaunamos, suintegravus funkcijas, i kurias jeina atitinkamai šeštojo ir aštuntojo laipsnio $L$-koordinačiu polinomai, naudojant analizinị integravimą pagal formulę [7]:

$$
\int_{\Delta} L_{1} L_{2} L_{3} d \Delta=2 \Delta \frac{a ! b ! c !}{(a+b+c+2) !}
$$

ir du skaitinio integravimo būdus, kurie toliau bus vadinami Gauso ir Radau metodu (naudojant Gauso ir 
Radau svorio koeficientus [12]) ir Hammerio metodu (naudojant Hammerio svorio koeficientus [13]).

Šeštojo laipsnio polinomui skaitiškai suintegruoti reikia ne mažiau kaip septynių integravimo taškų, aštuntojo laipsnio polinomui - ne mažiau kaip devynių tašku [12]. Deja, taikant Gauso ir Radau metoda integruojama arba keturiuose, arba devyniuose taškuose, taigi abiem atvejais tenka imti devynis taškus (1 pav.).

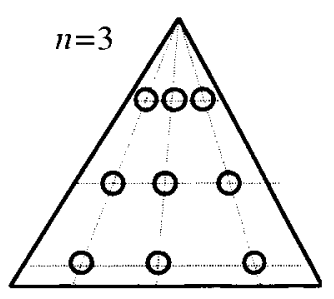

1 pav. Taškai, skirti integruoti trikampio plote GausoRadau metodu

Fig 1. Integrating points in a triangular region by GaussRada

Skaitinis integralas apskaičiuojamas pagal formulę [12]:

$$
I=\sum_{i=1}^{n} \sum_{j=1}^{n} W f\left(L_{1}, L_{2}, L_{3}\right),
$$

čia $f\left(L_{1}, L_{2}, L_{3}\right)$ - integruojama funkcija; mūsų atveju tai:

$$
f\left(L_{1}, L_{2}, L_{3}\right)=\mathbf{H}_{, i} \mathbf{H}_{, j}^{T}[F]^{T} \boldsymbol{\Psi}_{w} \mathbf{H}_{, k}^{T}-
$$

šeštojo laipsnio polinomu matrica, arba -

$$
f\left(L_{1}, L_{2}, L_{3}\right)=\mathbf{H}_{, i} \boldsymbol{\psi}_{w}^{T}[F]^{T} \mathbf{H}_{, j} \mathbf{H}_{, k}^{T}[F]^{-T} \boldsymbol{\psi}_{w} \mathbf{H}_{, l}^{T}-(18)
$$

aštuntojo laipsnio polinomų matrica.

$W$ - svorio koeficientai:

$$
W=A S(i) H(j)\left(1-L_{1}\right) .
$$

Integravimo taškụ koordinatès:

$$
\begin{gathered}
L_{1}=A I(i), \\
L_{2}=A J(j)\left(1-L_{1}\right), \\
L_{3}=1-L_{1}-L_{2}, \\
\quad i, j=1,2,3 .
\end{gathered}
$$

Funkcijų $A I(i), A J(j), A S(i), H(j) d$ reikšmès imamos iš lenteliụ [12].

Integruojant Hammerio metodu šeštojo laipsnio polinomui imami septyni taškai ( 2 pav., a), o aštuntojo laipsnio polinomui - devyni (2 pav., b).
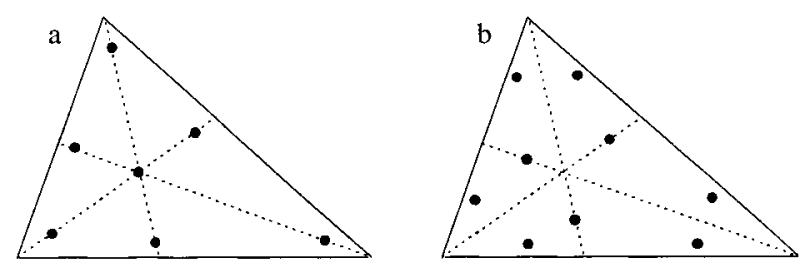

2 pav. Taškai, skirti integruoti trikampio plote Hammerio metodu: a) šeštojo laipsnio polinomui, b) aštuntojo laipsnio polinomui

Fig 2. Integrating points in a triangular region by Hammer: a) for sixth degree polynomial, b) for eighth degree polynomial

Skaitinio integravimo formule [13]:

$$
I=\sum_{i=1}^{n} W_{i} f_{i}\left(L_{1}, L_{2}, L_{3}\right)
$$

$n=7$ - šě̌tojo laipsnio polinomui; $n=9$ - aštuntojo laipsnio polinomui.

Hammerio svorio koeficientai $W_{i}$ ir taškų koordinatès imami iš lenteliụ [13].

Kaip matyti iš lentelès, kurioje pateiktas metodu efektyvumo palyginimas, tiek integruojant analiziškai, tiek ir skaitiškai, reikia atlikti labai daug aritmetiniụ veiksmų, nors skaitinio integravimo atveju ju reikia žymiai mažiau.

Verta pažymèti, kad pradinių poslinkių submatricas išreikšti, naudojant bazines matricas, reikia tik analiziniam integravimui, nes kiekvienas polinomo narys turi būti integruojamas atskirai. Tačiau, integruojant skaitiškai, sumuojamos pačios integruojamos funkcijos, taigi naudoti šiam tikslui išplèstas submatricas $\left[\mathrm{K}_{L i j}\right]$ (14) būtų labai neracionalu. Šiuo atveju reikia siekti kuo didesnio kompaktiškumo jau normuotujjų koordinačių ir mazginių poslinkiụ vektoriụ lygiu.

Pavyzdžiui, galima išskirti skaliarines dalis:

$$
\psi_{w}^{T} \mathbf{F}^{-T} \mathbf{H}_{, i}=\mathbf{H}_{, i}^{T} \mathbf{F}^{-1} \boldsymbol{\psi}_{w}=S_{i}
$$

ir apskaičiuoti jas atskirai kiekvienam integravimo taškui, iš integravimo lenteliụ ỉrašius atitinkamas integravimui paruoštas $\mathbf{H}_{, 1}$ ir $\mathbf{H}_{, 2}$ reikšmes ir koordinates, taip formuojant vektorius, kurių kiekvienas elementas yra skaliaro $S_{i}$ reikšmè vienam iteracijos žingsniui.

Savo ruožtu atskirais paprogramiais kuriamos ir (10×9) dydžio matricos $\mathbf{H}_{, 1}$ ir $\mathbf{H}_{, 2}$ kurių stulpeliai 
Integravimo metodų efektyvumo palyginimas, atsižvelgiant i gautu Fortrano paprogramiu slankiojo kablelio operacijų skaičiu Comparison of effectiveness of the integrating methods based on amount of floating point operations in FORTRAN subroutines

\begin{tabular}{|c|c|c|c|c|c|}
\hline \multirow{3}{*}{ Matrica } & \multicolumn{5}{|c|}{ Būdai } \\
\hline & \multirow{2}{*}{$\frac{\text { Analizinis }}{\text { operacijų }}$} & \multicolumn{2}{|c|}{ Gausso ir Radau } & \multicolumn{2}{|c|}{ Hammerio } \\
\hline & & tašku & operacijụ & taškų & operaciju \\
\hline \multicolumn{6}{|c|}{ Naudojant bazines matricas $\left[\mathrm{T}_{i, j k}\right]$ ir $\left[\mathrm{T}_{i, k, k}\right]$} \\
\hline$\left[\mathrm{T}_{i, j, k}\right]$ & $139 \cdot 10^{3}$ & 9 & $102 \cdot 10^{;}$ & 7 & $80 \cdot 10^{3}$ \\
\hline$\left[\mathrm{T}_{i, k, k}\right]$ & $1752 \cdot 10^{3}$ & 9 & $197 \cdot 10^{3}$ & 9 & $197 \cdot 10^{3}$ \\
\hline$\left[\mathbf{K}_{L}\right]$ & $18,6 \cdot 10^{6}$ & & $2,8 \cdot 10^{6}$ & & $2,6 \cdot 10^{6}$ \\
\hline \multicolumn{6}{|c|}{ Naudojant tarpinius vektorius ir matricas $\left[\mathbf{H}_{i,}\right],\left\{\mathrm{S}_{i}\right\},\left[\mathbf{H}_{i} \mathrm{~S}_{j}\right],\left[\mathrm{M}_{H S A d i}\right]$} \\
\hline \multirow{2}{*}[\mathbf{H}_{.i}]{} & & & & 7 & 193 \\
\hline & & & & 9 & 237 \\
\hline \multirow{2}{*}{$S_{i}$} & & & & 7 & 746 \\
\hline & & & & 9 & 950 \\
\hline \multirow{2}{*}[\mathbf{H}_{i,}\mathrm{S}_{j}]{} & & & & 7 & 75 \\
\hline & & & & 9 & 93 \\
\hline$\left[\mathrm{M}_{H S A i}\right]$ & & & & 9 & 634 \\
\hline \multirow{2}{*}{$\begin{array}{c}{\left[\mathrm{K}_{L i 3}\right.} \\
i=1,2,4,5\end{array}$} & & & & 7 & $60998 *$ \\
\hline & & & & 9 & $78378 *$ \\
\hline$\left[\mathrm{K}_{L 33}\right]$ & & & & 9 & 11859 \\
\hline \multirow{2}{*}[\mathrm{K}_{L}]{} & & & & $7 \operatorname{ir} 9$ & 72857 \\
\hline & & & & 9 & 87011 \\
\hline
\end{tabular}

* visoms keturioms matricoms skaičiuoti

* to have all four matrices calculated

yra normuotujų koordinačiu vektoriai $\mathbf{H}_{, 1}$ ir $\mathbf{H}_{2,}$, ịašius reikšmes iš integravimo lentelių. Po tam tikrų pertvarkymu matrica $\left[K_{L 33}\right]$ yra tokia:

$$
\begin{aligned}
& {\left[K_{L 33}\right]=\int_{\Delta}\left[B_{L}^{b}\right]^{T}[A]\left[B_{L}^{b}\right] d \Delta=[F]^{-T} \times}
\end{aligned}
$$

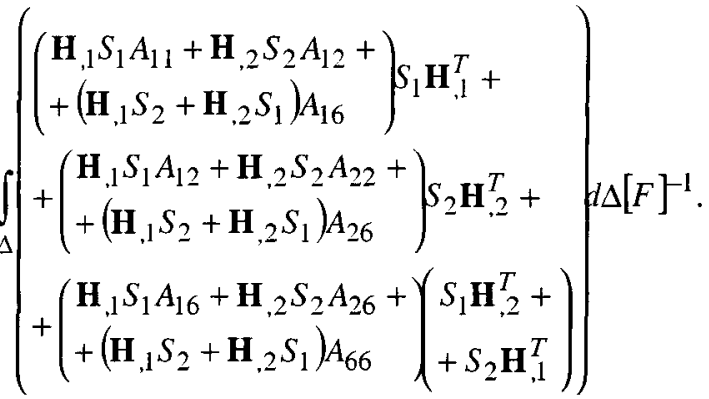

Kadangi sandaugos $\mathbf{H}_{, i} S_{j},(i, j=1,2)$ ieina i (23) išraišką po penkis kartus, jas taip pat verta suskaičiuoti iš anksto. Tai irgi bus $(10 \times 9)$ dydžio matricos. Submatricos $\left[\mathrm{K}_{L 33}\right]$ skaičiavima galima dar labiau supaprastinti, kadangi ji yra simetriška.
Panašūs pertvarkymai atliekami su kitomis $\left[\mathrm{K}_{L i j}\right]$ submatricomis. Kadangi matrica $\left[\mathrm{K}_{L}\right]$ yra simetriška, be $\left[\mathrm{K}_{L 33}\right]$, belieka suskaičiuoti keturias submatricas. Submatricos $\left[K_{L 13}\right]$ išraiška, naudojant skaitinị integravima:

$$
\begin{aligned}
& {\left[K_{L 13}\right]=\int_{\Delta}\left[B^{p l}\right]^{T}[A]\left[B_{L}^{b}\right] d \Delta=[F]^{-T} \times} \\
& \left(\sum_{i=1}^{n} w_{i}\left(\begin{array}{c}
\left(\mathbf{H}_{, 1} S_{1}\right)_{i}^{T}\left(A_{11}\left(\mathbf{H}_{, 1}^{T}\right)_{i}+A_{16}\left(\mathbf{H}_{, 2}^{T}\right)_{i}\right)+ \\
+\left(\mathbf{H}_{, 1} S_{2}\right)_{i}^{T}\left(A_{12}\left(\mathbf{H}_{, 2}^{T}\right)_{i}+A_{16}\left(\mathbf{H}_{, 1}^{T}\right)_{i}\right)+ \\
+\left(\mathbf{H}_{, 2} S_{1}\right)_{i}^{T}\left(A_{66}\left(\mathbf{H}_{, 2}^{T}\right)_{i}+A_{16}\left(\mathbf{H}_{, 2}^{T}\right)_{i}\right)+ \\
+\left(\mathbf{H}_{, 2} S_{2}\right)_{i}^{T}\left(A_{26}\left(\mathbf{H}_{, 2}^{T}\right)_{i}+A_{66}\left(\mathbf{H}_{, 1}^{T}\right)\right)
\end{array}\right)\right) F J^{-1},(24)
\end{aligned}
$$

$w_{i}$ - Hammerio svorio koeficientai; $n=7$ arba $n=9$ priklausomai nuo pasirinkto integravimo tikslumo. Iš pirmo žvilgsnio gali atrodyti, jog būtų racionaliau submatricoms $\left[\mathrm{K}_{L 13}\right],\left[\mathrm{K}_{L 23}\right],\left[\mathrm{K}_{L 34}\right]$ ir $\left[\mathrm{K}_{L 35}\right]$ naudoti tas pačias $\left[\mathbf{H}_{, i}\right],\left\{S_{i}\right\},\left[\mathbf{H}_{, i} S_{j}\right\rfloor(i, j=1,2)$ išraiškas, ku- 
rios buvo naudojamos submatricai $\left[\mathrm{K}_{L 33}\right]$ gauti, t. y. naudoti didesni, negu reikia, integravimo tikslumą $(n=9)$, kad nereikètụ perskaičiuoti minètụ tarpiniụ vektoriụ ir matricu, kai $n=7$.

Tačiau, naudojant MATHEMATICA, išvedus reikalingus paprogramius, paaiškejo (žr. lentelę), kad, kai integravimas yra pakankamai tikslus (t. y. atskirai skaičiuojami tarpiniai vektoriai ir matricos, kai $n=7$ ir kai $n=9$ ), bendras operacijụ skaičius matricai $\left[\mathrm{K}_{L}\right]$ suskaičiuoti yra mažesnis.

\section{Išvados}

Taikant kompiuterinès algebros technologija buvo integruoti šeštojo it aštuntojo laipsnio polinomai ir gautos pradinių poslinkių matricos geometriškai netiesiniam sluoksniuotajam baigtiniam elementui TRIPLT.

Išanalizavus integravimo rezultatus, galima teigti kad:

1. Taikant skaitini integravimą slankiojo kablelio operacijų skaičius yra pakankamai mažas. Tai leidžia realizuoti programą plačiai prieinamomis kompiuterinémis priemonèmis, taigi šiuo atžvilgiu nėra ypatingų kliūčių geometrini netiesiškumą efektyviai taikyti TRIPLT tipo baigtiniam elementui.

2. Kompaktiškiausi paprogramiai gaunami polinomus integruojant skaitiškai, su Hammerio koeficientais, naudojant tarpinius vektorius ir matricas.

3. Šeštojo laipsnio polinomui integruoti nebūtina taikyti Gausso ir Radau metodą: integravimo tikslumui nereikia šiam elementui devynių taškų, bet šiuo atveju devyni taškai - tai minimumas, kuris būtinas taikant ši integravimo metodą.

4. Aštuntojo laipsnio polinomo integravimo išraiškos turi beveik vienodą operaciju skaičiu tiek taikant Gausso ir Radau metoda, tiek Hammerio. Kadangi taikant Hammerio metodą integravimo taškai trikampio plote išdèstomi simetriškai ( 1 pav. ir 2 pav. b), už Gausso ir Radau metodą jis turètu būti efektyvesnis ir šiuo atveju.

5. Ivertinus tai, kad analizinio integravimo rezultatas yra tikslus (kiek leidžia kompiuterinis skaičiavimas), nebūtina visiškai jo atsisakyti. Jis gali būti taikomas, konstrukcijas skaičiuojant su galingais kompiuteriais, kurie gali atlikti kelis milijonus operacijụ per sekundę.

\section{Literatūra}

1. ABAQUS/Explicit Product Description Version 5.8. URL http://www.hks.com/products/p_abexplicit.html, 1999.

2. ALGOR. Physics-Based Mechanical Event Simulation and Nonlinear Stress Analysis. URL: http:/www.algor.com/ homepag3.htm, 1999.

3. ANSYS 5.5 Update: Quick Reference Guide. ANSYS/ Structural. URL: http:// www.ansys.com/Products/ Ansys55/whatisnew/str.html, 1999.

4. COSMOS/M Version 1.75 for Windows NT \& 95. Electronic documentation, 1998.

5. Modelling laminates. Fracture Research Group. University of Bristol. URL: http://www.fen.bris.ac.uk/mech/research/ material/projects/laminate.htm, 1999.

6. H. V. Lakshminarayana, S. Sridhara Murthy. A Shear-flexible Triangular Finite Element Model for Laminated Composite Plates // Int. J. Numer. Meth. In Engng. 20, 1984, p. 591-623.

7. R. Belevičius. Computer Algebra in Finite Element Method. Vilnius: Technika, 1994. $184 \mathrm{p}$.

8. V. Kulinič. Non-Linear Analysis of Reinforced Concrete Beams Using Laminated Element. M.Sc. thesis. Vilnius, 1995. $70 \mathrm{p}$

9. R. M. Jones. Mechanics of Composite Materials. McGrawHill, 1975. $383 \mathrm{p}$

10. J. R. Vinson. R. L. Sierakowski. The Behavior of Structures Composed of Composite Materials. Martinus Nijhoff, 1986. $253 \mathrm{p}$

11. В. П. Дьяконов. Системы символьной математики Mathematica 2 и Mathematica 3. Москва: СК ПРЕСС, 1998. $328 \mathrm{c}$

12. O. C. Zienkiewicz, R. L. Taylor. The Finite Element Method. McGraw-Hill, 1971. 538 p.

13. G. R. Cowper. Gaussian Quadrature Formulas for Triangles // Int. J. Numer. Meth. in Engng., 1972, p. 1862 1868.

Iteikta $2001 \quad 1018$

\section{COMPARISON OF COMPUTER-AIDED INTEGRATION TECHNIQUES WHEN OBTAINING INITIAL DISPLA- CEMENTS MATRIX FOR GEOMETRICALLY NON- -LINEAR LAMINATED FINITE ELEMENT}

\section{Kulinič}

Summary

Geometrical non-linearity of the laminated element has not been realized so far in the widely known commercial finite element method packages such as ABAQUS, ALGOR, ANSYS, COSMOS although researches in that field are actively carried out. On the other hand, there is a lot of problems where large displacements and deformations must be dealt with to obtain a precise decision. 
A wide range of composite orthotropic materials is used in constructions and other fields of technology. Various numerical methods were implemented to handle laminated plates and shells, however most of them are intended for application only with particular types of the structures.

The author's aim is to develop a geometrically nonlinear finite element that could be effectively used for analysis of various laminated slabs regardless of their shape, thickness of laminae, properties of materials, direction of orthotropy axes, way of loading and boundary conditions.

Obtaining and handling the element's initial displacement matrix used in the iteration process is a highly complicated issue requiring significant amount of computer resources to be involved. One of the most important aims of the research is to develop an element which could be used not only in an expensive multiprocessor mainframes, but also in an usual personal computer.

For the structure, a sophisticated finite element TRIPLT having 50 degrees of freedom is used. The geometrical matrix for this element is obtained involving L-coordinates' array while displacements and rotations in the middle of the element are expressed through the nodal displacements (rotations), their derivatives, and displacements (rotations) in the central point. Linear and non-linear components for the geometrical matrix are shown in Eqs 2 and 5.

The behaviour of a geometrical non-linear finite elements structure is described by $\mathrm{Eq} 8$. The tangent stiffness matrix consists of the conventional linear elastic stiffness matrix, initial stress matrix and initial displacements matrix which is obtained by $\mathrm{Eq} \mathrm{10,} \mathrm{using} \mathrm{both} \mathrm{analytical} \mathrm{and/or} \mathrm{numerical}$ integrating.
The analytical integrating involves expanding of the appropriate expressions into basic matrices (Eqs 11, 12) and using formula 15. The initial displacement matrix in term of constitutive matrix's elements and the basic matrices is shown in Eqs 13 and 14.

Numerical integrating is conducted by two methods: those using Hammer and Gauss-Radau weight coefficients. Numerical approach is applied both to the basic matrices and factorised expressions of submatrices involving intermediate arrays and matrices (Eqs 23, 24).

Two ways of obtaining the intermediate arrays and matrices are discussed.

Because of high complexity of the procedures involved the computer algebra system Mathematica was used for the integrating and recording FORTRAN codes.

Comparison of the effectiveness of all the procedures is presented in a table.

The investigation results show that the initial displacement matrix obtained by means of numerical integration involves a small amount of arithmetic operations to be handled with a usual personal computer.

Valentinas KULINIČ. MSc (Eng). Vilnius Gediminas Technical University (VGTU), Saulètekio al. 11, LT-2040 Vilnius, Lithuania. E-mail: valentinas@tilde.lt

A graduated of the VGTU (1994, civil engineer). MSc (1995). Project manager (Tilde IT Ltd.). Research interests: non-linear structural analysis, object-oriented and componentbased finite element programming, mechanics of concrete. 